\title{
On the Implementation and Impacts of the "Burden Reduction" Mode for the Growth of Primary and Middle School Students
}

\author{
Yan Linjing ${ }^{1}$ \\ ${ }^{1}$ Beijing Polytechnic \\ Beijing, 100176, China
}

\begin{abstract}
Through the investigation of the current learning situation of primary and middle school students from multiple dimensions and the statistical analysis based on the survey data, this paper illustrates the beneficial effects of the rich after-school life and full development of individual abilities brought about by the "burden reduction" while reflects the quality decline caused by the "burden reduction". At the same time, this paper also puts forward constructive solutions for the effective and highquality implementation of "burden reduction" and provides references for the teaching reform of primary and middle schools.
\end{abstract}

Keywords-Primary and middle school students; Burden reduction; Growth; Impact

\section{INTRODUCTION}

Primary and middle school students is a very special learning group with unique advantages in memory, thinking and creativity. It is this group of people who carry the future and hope of our nation. As a result, the cultivation of highquality next generation has always been the unshirkable responsibility and mission of great urgency for educators.

As a matter of fact, our educational evaluation mechanism has determined our education model for a long time. The Premier has said in his government work report in 2008 that to pull off a good job in all types of education at all levels, we must finish three tasks. The first of them is the "all-round implementation of quality education and the promotion of education reform and innovation. Deepen the reform of teaching content and methods, examination and enrollment system and quality evaluation system. Reduce the academic burden of primary and middle school students conscientiously, provide a good school experience to children, do a good job of education that can be recognized by people and improve the quality of the entire nation." All of them are excellent suggestions and ideas as well as outstanding intentions and prospects. However, have these prospects been implemented ideally? The following things are what we need to do from the perspective of quality education. We need to cultivate children's non-intellectual ability for all-round development and reform the existing strict and harsh examination system; We need to implement new curriculum standards in the context of quality education, pay attention to the process of discovery and the ability to develop thinking while reduce the use of eccentric and odd quiz in examination. We need to implement the quality education program in accordance with the new curriculum standards, rather than conduct unrealistic competitions over entrance exam performance. We have been chanting "burden reduction" for many years. Well, how well does it work? What aspects need to be improved continuously? This paper conducted a targeted investigation and analysis.

\section{THE ANALYSIS OF THE SURVEY RESUlts}

\section{A. Analysis of the characteristics of research objects}

\section{1) Role features}

The sample size of this survey totaled 549, including 313 students, 204 parents, and 32 teachers. 


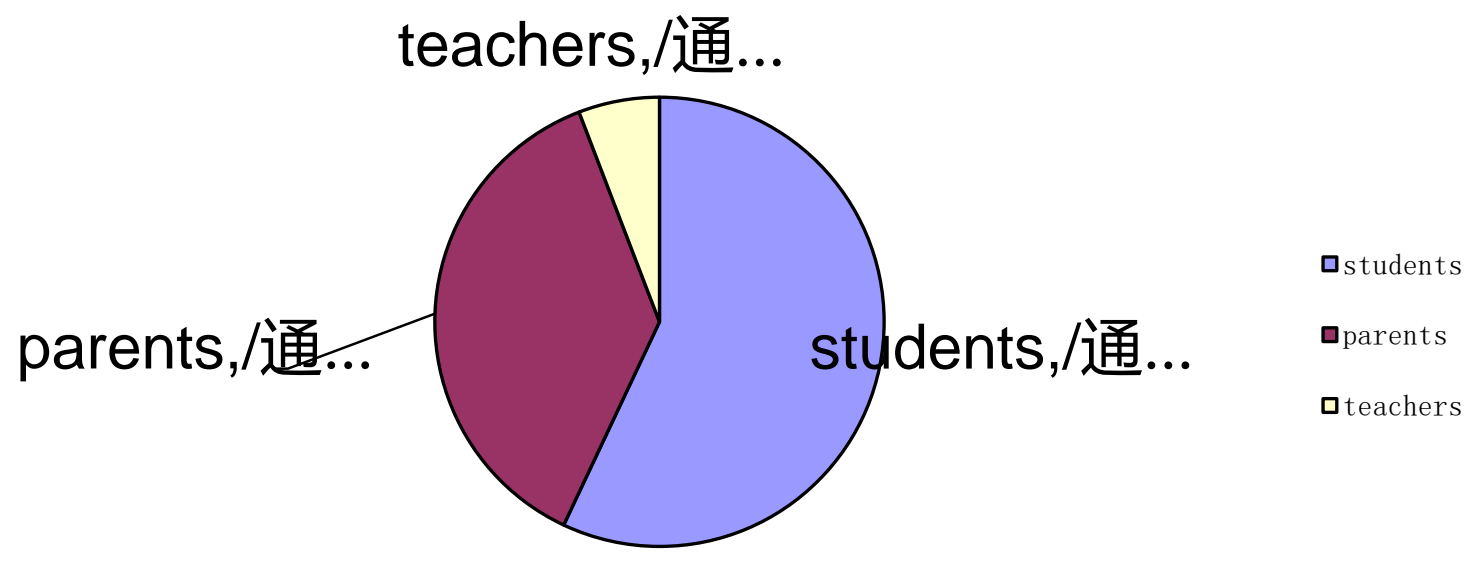

Fig. 1 Sample structure in terms of role

2) Grade features of students

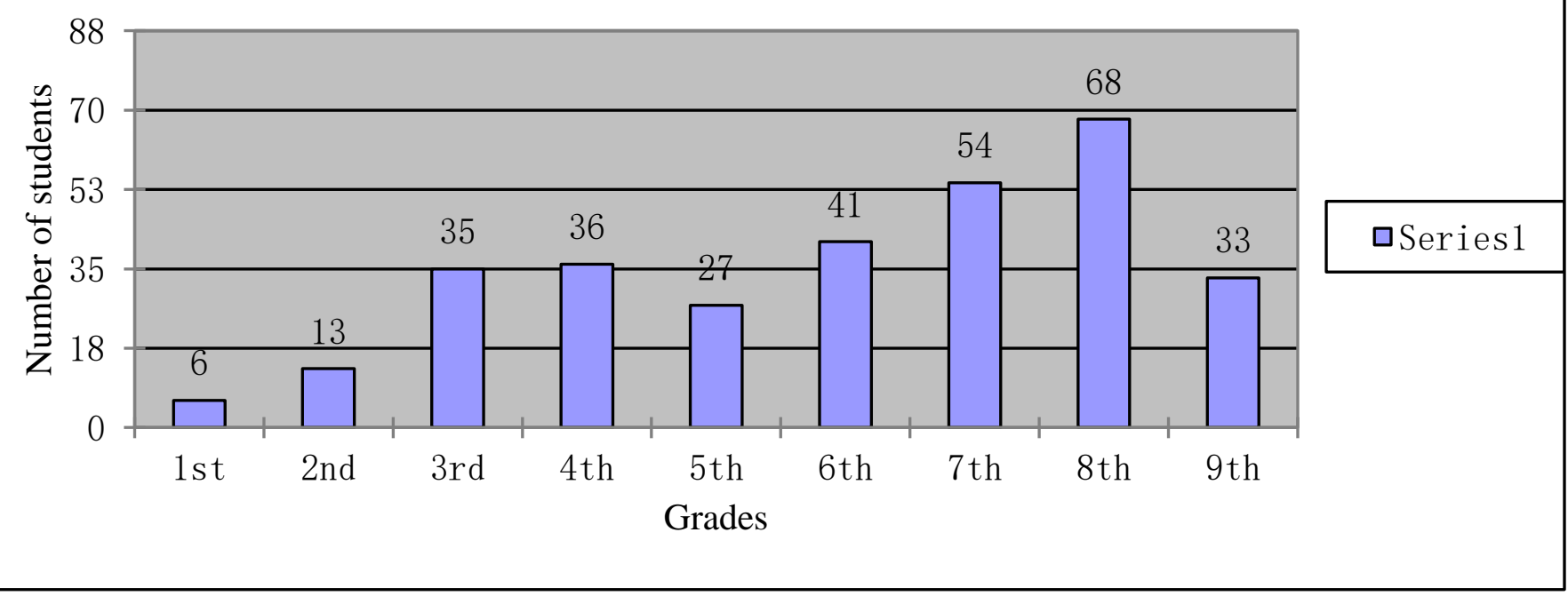

Fig. 2 Grades distribution of students

\section{B. Analysis of the Survey Data}

1) Analysis of students' workload (measured by the time needed)

The student's after-school workload is an important indicator for measuring whether they are overloaded academically, while this indicator is closely related to the student's learning environment. The survey shows that lower grades of primary schools bear little or no homework at all compared with the workload for higher grades that increased by leaps. Besides, the homework assignments in higher grades of key primary schools and key middle schools are significantly heavier than those of ordinary schools. What's worse, data prove that $80 \%$ of the students in key schools spend more than two hours every day on homework or even longer. That's exactly why they remain as key schools. The facts mentioned above also reflect that most homework aims at repeated mechanical memory and the drawbacks of the assessment method. 
2) Analysis of students' freedom (measured by extracurricular time)

The extracurricular time for students stands out in stark contrast to the time they spend on homework. Different from the above results, nearly $90 \%$ of students ranging from higher grades in primary school to middle school interviewed say that they almost have no free time for playing. Then, how does the playing time disappear? Based on further statistics, we can draw the following conclusion: a lot of time has been wasted! Why is this happening? There's an alarming truth behind it. $70 \%$ of the students think that the homework is boring and have no interests in it. They do their homework just for the convenience of handing it over. As a result, they do homework in an inefficient way. Teachers express unanimously that homework is an unavoidable way to improve students' performance according to their questionnaires. It is undeniable that there is a problem with our assessment mode. A test paper that only centered on rote rather than critical thinking has stifled unlimited creativities of both teachers and students.

3) Analysis of the indicators of students' mental health (measured by perceived learning pressure)

According to the survey data, primary school students feel comparatively less learning stress, which is related to their psychological growth stage. As far as they're concerned, pressure is the supervision of teachers and parents and the lack of free time to play as they have never experienced discomfort psychologically. As a result, $86 \%$ of the primary school students believe that their current study is generally enjoyable. Middle school students' pressure feelings are more obvious in this area, especially those in key schools. The data show that students' sense of stress is directly related to their schools, thus the data comparison gains a more important status. The survey contains 155 middle school students, including 84 students from key schools, 55 from general schools and 16 from migrant schools. $97 \%$ of the students from key schools think they are under excessive learning pressure among which $25 \%$ come from the further education, $45 \%$ from their parents, $20 \%$ from their teachers and $10 \%$ from themselves. It's obvious that the pressure of students is largely imposed by their teachers and parents and this shows that the urgency students displaying is a false mask. In conclusion, "burden reduction" is essential not only to students, but also to teachers and parents!

\section{4) Analysis of students' creativity coefficient}

The creativity of student comes from classroom practice time, spare time, and extracurricular interest activities time. If allocate coefficients in a ratio of $2: 1: 2$, the three factors mentioned above will account for $0.4,0.2$, and 0.4 respectively.

TABLE I Calculation of freedom in terms of classroom practice (in the case of 30 lessons per week)

\begin{tabular}{|c|c|c|c|c|}
\hline Classroom practice time & $>=15$ & $10-15$ & $6-10$ & $3-6$ \\
\hline $\begin{array}{c}\text { Freedom coefficient in } \\
\text { classroom }\end{array}$ & 1 & 0.7 & 0.5 & 0.3 \\
\hline
\end{tabular}

TABLE II Calculation of freedom in terms of spare time (in the case of 30 lessons per week)

\begin{tabular}{|l|l|l|l|c|}
\hline Spare time & $>14$ hours & $10-14$ & $6-10$ & $3-6$ \\
\hline Freedom coefficient & 1 & 0.7 & 0.5 & 0.3 \\
\hline
\end{tabular}

TABLE III Calculation of freedom in terms of extracurricular interest activities

\begin{tabular}{|c|c|c|c|c|}
\hline $\begin{array}{c}\text { Time for extracurricular } \\
\text { interest activities }\end{array}$ & $>10$ hours & $6-10$ & $4-6$ & $2-4$ \\
\hline Freedom coefficient & 1 & 0.8 & 0.5 & 0.2 \\
\hline
\end{tabular}

According to the calculation of freedom coefficient, it's found that the mean value of the data is 0.5 , with freedom coefficient of key schools' students averaged at less than 0.4 and that of general schools' students averaged at somewhere between 0.5 and 0.6. Meanwhile, it shows that the freedom level of students, which also directly curbs the creativities of students, is generally low and far from reaching the ideal value [1-2].
5) Analysis of students' physical development indicators (measured by students' sleep time)

Sufficient sleep is the basic guarantee for the study and life of a student. Sleep needs can be varying among different age groups. The results of the survey are still closely related to the students' schools. Most students in key schools are troubled by insufficient sleep with $83 \%$ of them suffering from sleep deprivation. Some of them even get a sleep time level that 
lower than the sleep threshold of the elderly people. This phenomenon directly affects the life qualities of students.

\section{Analysis of the Survey Results}

\section{1) Analysis of the essence of "burden reduction"}

"Burden reduction", or reduction of educational burden, doesn't equal to quality decline. The main purpose of burden reduction is to reduce students' pressures and free them from overloaded academic workloads in a bid to achieve comprehensive development on five aspects of morality, intelligence, physique, aesthetics and labor as well as to improve the overall quality of students comprehensively. Therefore, "burden reduction" is the goal rather than a process or a method.

Firstly, confronted with burden reduction, we must be keenly aware that simply reducing the amount of homework is not enough to achieve the goal of "burden reduction".

Secondly, burdens for parents, teachers and students are all too great to bear. In some cases, burdens of parents and teachers are much greater than those of students. Therefore, the three roles mentioned above are all in need of "burden reduction", which is a mutual restraint process.

Thirdly, only by simultaneously reducing the pressures of these three groups of people can we gradually enter the process of "educational burden reduction".

Fourthly, the essence of "educational burden reduction" is to realize the integration of educational ideas, education systems, curriculum systems, classroom teaching models, classroom teaching methods and measures.

Fifthly, the ultimate objective of "burden reduction" is to achieve the all-round development of young people.

\section{2) Influencing factors and determining factors of "burden reduction",}

The difficulties in reducing the severe learning burdens for students in primary and middle schools have become a problem for the basic education. The manifold reasons behind this phenomenon can be reduced to the following:

\section{a) Traditional beliefs}

An important reason lies behind the low efficacy of current "burden reduction" efforts is that traditional belief of talent is still deeply rooted in people's minds. Modern people have been profoundly influenced by the traditional education, including cherishing teaching over learning, respecting teachers over students, valuing knowledge over ability, and appreciating theory over practice and rating sense over sensibility. Therefore, from the perspective of talents, modern people prefer knowledgeable talents with solid knowledge and basic skills. As a result, the cultivation and development of a student's personality, emotion, and healthy characters has been ignored. In the minds of students and their parents, only through step-by-step development, which means to study hard and then go to a college or a key university, can a student become talent and make achievements. This belief coupled with the deep-rooted idea of traditional talent due to its long existence is what make the work of "burden reduction" hard to conduct and produce very little effect [3].

\section{b) Social environment}

The fundamental reason that curbs the implementation of "burden reduction" is the student's future, in other words, the employment prospects of students. Against the backdrop of large population and excessive employment pressure in our country, competition has become the only mechanism. It's hard to make the test-oriented education mechanism featured with survival of the fittest a thing of past. To enhance their career competitiveness, the pressures from students themselves, parents, classmates and teachers have evolved into an obstacle that hampering "burden reduction", especially in primary and secondary education. To cope with "selection examination", teachers will inevitably make teaching harder and increase teaching time and workload. As a result, students' learning burdens get heavier.

A profound regional economic background is also a reason at play when it comes to the phenomenon of overburdened students in primary and middle schools. To some extent, the phenomenon of overburdened students is a chain reaction caused by the imbalance of regional economic development in our country. The poorer regional economy a student living in, the firmer he or she believes in that knowledge can change destiny. While students living in regions of higher economy level want to get even better and have a strong desire to distinguish themselves from their counterparts [4].

\section{c) Educational system}

Personally, the decisive factor which restricts the implementation of "burden reduction" still lies in the educational systems in China. The details are described as follows:

(1) Unmatched Educational Concepts and Educational Goals

What we hope to cultivate is well-rounded adolescents, but there is no doubt that not all adolescents can achieve the goal to be well-developed. However, China's education, under the guidance of the educational concepts in China, is trying to get all young people to achieve this common goal. The lack of diversity and differentiation in education hinders the practical implementation of an advanced educational concept.

\section{(2) Disjointed Assessment Mechanisms at All Levels}

The work to relieve burdens for those students in primary and secondary schools should go on until they enter a college or university for higher education. Here the college entrance examination will be left aside but more attention will be paid to those who are going to enter a junior high school from a primary school or to enter a high school, and it is found that the educational and teaching concepts and the educational assessment mechanisms are seriously disconnected. On the one hand, those schools pay much attention to quality education to improve self-development of students, hoping students to obtain abilities in self-exploration and pay less attention to test grades; on the other hand, they ultimately aim at good scores. At present, good reform measures are being carried such as universal popularization in connecting primary schools with junior high schools and reduction in numbers of those students who are privileged to choose school. We 
believe the measures mentioned above are good enough to solve the problem and will be effective.

However, problems are remained unsolved. We assume that students in junior high schools succeed in practicing the concept of quality education and developing students' imagination and creativity so that they can truly enjoy the learning under this mode. However, when those students graduate from junior high school, they must face a hypercompetitive examination to go into a good high school, which can change the fates of many graduates. To obtain a high college enrollment rate which is based on college entrance examination, high schools have made students' entrance grades of high school the only screening criteria to choose students, thus the students will face a more severe elimination mechanism.

In summary, it is not difficult to find that the current examination system hampered the reduction of students' burden of further education; and the students can never manage to throw off the yoke imposed by the excessive anxieties of their parents and the pressures slapped by their teachers. All these factors left "burden reduction" a long way to go.

\section{d) Quality of Teaching Staff}

Currently, the quality of teachers in primary and secondary schools in China is also an important factor resulting in the excessive burden of students. Except for a few teachers who are in lack of professionalism and responsibility, most teachers are conscientious and diligent. However, the common problem is that most of them lack the innovation of teaching ideas and effective means to alleviate burden on students without degrading the teaching quality. At the same time, teachers have been subject to various shackles which deprived their freedom to implement a lively classroom trials and innovate. They have no choices but cramming and assigning a large amount of homework and examination to enhance students' learning motivation, which in turn increases the students' learning burden.

\section{3) The contradiction brought about by "burden reduction" and the solution to its implementation}

The burden-reduction policy has been carried out for many years. Indeed, the time that primary students spend at school is much less and the written homework of middle school students hasn't increased. But the contradictions have increased enormously compared with the past. Parents have no time to pick up their children, so what shall they do? Asking for leave from work every day, hiring a babysitter, or just leaving their poor children at extra-curricular classes? The schools are no longer allowed to take make-up class but examinations remain as difficult as before and examination systems remain unchanged. So what can parents do? Teach their children in person or send them to a remedial class? Extracurricular classes are rich and colorful while education at school is questioned?

"Burden reduction" is a systematic project. It is not just involving simple reduction. To implement "burden-reduction", many parties such as schools, the society and families must make concerted efforts so that an expected goal can be achieved via comprehensive management. According to this paper, the following countermeasures should be taken:

(1) Focus on the publicity of education and public opinion orientation, change the traditional concepts in educating, and establish a scientific concept to develop talents by quality education

Focused on all-round development in morality, intelligence and physique, quality education is a kind of sustainable development education in which students' physical and mental health is required in a bid to cultivate pioneering talents with innovative spirit, ability and level. That change people's deeprooted traditional concepts in education through promoting quality education vigorously is a prerequisite for the promotion and realization of quality education.

(2) Guarantee the completeness of educational systems and effectively reduce the disconnection among evaluation systems at all levels

To alleviate the excessive learning burden of primary and secondary school students in a fundamental way, it is necessary to reform the current education system, education input and distribution mechanism on the basis of changing the previous educational concepts, and to establish and improve relevant systems, especially changing evaluation methods when students entering junior high school from a primary school and entering high school from a junior high school so as to make the quality education develop sustainably. We need to reform the unreasonable educational evaluation system in the past which takes score as the only standard to evaluate a student, a teacher and a school, and to establish a new type of educational evaluation system that is conducive to mobilizing students, teachers, and parents. The guiding and stimulating function of educational evaluation systems need to be fully played. At the same time, when people are no longer trapped into enormous pressure, students will have more time for afterclass activities. School and even the whole society is obliged to provide students with places for healthy and beneficial activities, carry out rich and colorful after-school activities and mobilize students' various interests so as to promote physical and mental health as well as comprehensive development of students.

(3) Change the traditional classroom teaching mode, and promote quality education throughout the process.

The survey data shows that students are generally more interested in open classrooms, which not only caters to their physiological and psychological developmental characteristics, but also becomes an effective way to promote quality education in theory and practice. Therefore, in order to reduce the burden while at the same time keep the educational quality, we must reform the teaching mode, break the closure in content and form of classroom, and build a new model in the openness. The methods thereof are flexible, which need joint efforts of the teaching staff, and the sharing of resources.

For example, we can change the classroom to stimulate students' interest in learning and mobilize their enthusiasm for learning so as to develop their creativity; practices can open up the horizons of students and develop ideas that can help students apply what they learned at classes to daily lives; 
educational teaching tools in modern society can also be used to increase amount of information that students can accept and to develop students' ability in applying and processing information [6].

(4) Strive to improve the management and innovation level of leaders at school, cultivate teachers' education and teaching level, gradually create an interesting school life, develop a colorful and amusing classroom, and make the life at school a happy memory for students.

For students, school is their "home" which they can't live without. "Advanced education and teaching concepts" as well as leaders who are "bold", "innovative" and "pragmatic" are needed to build a platform for students and teachers. Outstanding teachers are needed to put it into practice. In the aspect of teacher training, incentive mechanism, communication mechanism and co-sharing mechanism can be utilized to motivate the enthusiasms of teachers. By promoting outstanding achievements of teachers, we hope to gradually spread influence of those pioneering teachers and to improve further innovation and progress. It is a great achievement that cannot be done in a short term, but we will seize every minute to fight for it.

\section{SUMMARY}

Marx once said: "Freedom is the precondition of creation". Our "burden reduction" today also aims at returning the freedom to students. To achieve this goal, the attention and recognition from the whole society, the understanding and approval of all citizens on the "burden-reduction" values and view of development are required. It is necessary for the great people in the education sector to stand on the shoulders of predecessors and to implement reforms on educational systems. In addition, we need our excellent teachers to work hard so that the burdens of students on rote learning can be reduced and space for creative thinking can be allocated; the burdens of students on uniform task can be alleviated and students therefore can choose what homework that will do; a classroom with a single teaching mode can be transformed into a comprehensive process to promote the development of students' personalities, enrich the spiritual world of students, enlighten students' minds and boost all-round development of students; the process to duplicate, produce, process and package the knowledge of predecessors can be changed into a process in which students are willing to accept and develop a new thinking; the process of cramming is turned into a process which focuses on knowledge retrieval and discussion as well as abilities of students in exploration and research; and a process with the single teaching and learning purpose can be changed into a process in which learning is made for development and innovation [5].

It is still a long way ahead of us to alleviate the burdens of students. Let's work together to ensure that the healthy and happy teenagers can live in a harmonious and vigorous environment!

\section{REFERENCES}

[1] Zhang Canpeng, Guo Xianchang. Market Research and Analysis Forecast [M]. Beijing: Tsinghua University Press, 2008, 3: 49-55. (In Chinese)

[2] Chen Zhenghan. Analysis on College Students' Online Shopping Behavior [J]. Sales and Marketing, 2007(6):34-36. (In Chinese)

[3] Song Naiqing, Yang Xin, Wang Dinghua, Zhu Dequan. Research on the Construction of Student's Academic Burden Evaluation ModelTaking Students in Compulsory Education as an Example [J]. Journal of Southwest University (Social Science Edition).2015(03). (In Chinese)

[4] Lan Shanqing. How to evaluate the quality of compulsory education? [J]. Management of Primary and Secondary School. 2007(05). (In Chinese)

[5] Tu Yumei, Yuan Yang. Research on the Balance of Compulsory Education Quality and Its Influencing Factors [J]. Educational Research \& Experiment. 2013(06). (In Chinese)

[6] Yang Xin; Luo Shiyan; Song Naiqing; Zhu Dequan; Li Sen; Zhang Huirong. A Study on the Evaluation of "Burden Reduction and Quality Improvement" in China's Compulsory Education: A Report Based on Third Party Assessment of Compulsory Education. Educational Management Research. 2016(06). (In Chinese) 